\title{
A poética knopfliana: de sussurros abafados à alongada voz do silêncio
}

\author{
Paula Terra Nassr ${ }^{1}$ \\ Para o Daniel, \\ porque entre o silêncio e os \\ sussurros, existe o sentido!
}

Resumen: El periodo colonial trajo a las tierras africanas sufrimiento y sumisión y, a remolque, hizo emergir sujetos paridos de la mezcla cultural. Este artículo versa sobre la obra poética de Rui Knopfli, descendiente de europeos, nacido em Mozambique, que fijó, a lo largo de su poética, un discurso híbrido en el intento de escapar de la amenaza permanente de diluirse en migraciones íntimas. Está latente en sus poemas un sujeto escindido que lucha contra el silenciamento sistemático traído por la revolución anti colonial.

Palabras clave: Rui Knopfli, Poesía, Literatura Mozambicana, Sujeto, Hibridismo.

Resumo: $\mathrm{O}$ período colonial trouxe às terras africanas sofrimento e submissão e, a reboque, fez emergir sujeitos paridos da mescla cultural. Este artigo versa sobre a obra poética de Rui Knopfli, descendente de europeus, nascido em Moçambique, que fixou, ao largo de sua poética, um discurso híbrido no intento de escapar da ameaça permanente de diluir-se em migrações íntimas. Fica latente em seus poemas um sujeito cindido que luta contra o silenciamento sistemático trazido pela revolução anti colonial.

Palavras-chave: Rui Knopfli, Poesia, Literatura Moçambicana, Sujeito, Hibridismo.

Quando em 1960, centenas de jovens manifestantes ergueram as bandeiras da FLN (Frente de Libertação Nacional) na ilha de Moçambique estavam anunciando um alinhamento ideológico com os nacionalistas africanos das colônias portuguesas de Angola, da Guiné-Bissau, das ilhas de Cabo Verde e das ilhas de São Tomé e Príncipe. Esse movimento de sentidos na malha social indicava, ademais do anseio fundante de um Estado independente e de Direito, a partir das ruas do bairro de Salermbier, tensões gestadas por um sistema colonial injusto, severo e que apresentava um processo de franco declínio, além, obviamente, de sua extemporaneidade latente. O resultado dessa sublevação se veria no 
golpe militar ocorrido em 1974 que levou a cabo a onipresença administrativa do regime salazarista nas colônias portuguesas na África. É nesse efervescente momento histórico que Rui Knopfli começa a produzir e a publicar seus poemas que vão retratar um sujeito sedento por liberdade, mas que ao mesmo tempo, não rompe totalmente com a influência dos séculos de dominação europeia.

Ergue-se nesse contexto e nesse labor poético um sujeito que vive no intermédio das culturas europeia e africana e que ousa dizer-se produto das duas: "Não sei se o que escrevo tem a raiz de algum/ pensamento europeu./É provável... Não. É certo,/mas africano sou" (KNOPFLI, 2003, p.59).

O discurso poético do escritor moçambicano Rui Knopfli compõe uma obra poética menos engajada, em relação ao discurso pós-colonial vigente na época da libertação moçambicana do jugo colonialista português. Muitos de seus contemporâneos como Noémia de Sousa, Orlando Mendes, José Craveirinha, Rui Nogar, Virgílio de Lemos, entre outros, produziam uma literatura mais voltada para o momento sócio-político e alçavam seus discursos pelo viés do discurso da negritude, de acordo com Laranjeira (1995), do nacionalismo e buscavam a expansão das vozes silenciadas pelos colonizadores, visto que estes ao largo de cinco séculos impuseram sua língua e seus hábitos. Como observa Abdala Junior (2007, p. 37), o processo "de aculturação do colonialismo português visava à desculturação dos outros povos. Se Portugal impôs seus padrões, também foi marcado, por sua vez, pelo sistema que estabeleceu, ao voltar-se obsessivamente para o sonho do "ultramar".

Pode-se perceber no fragmento que, embora houvesse uma imposição cultural por parte da metrópole, havia também uma influência da cultura do colonizado, estabelecendo um processo dialógico de edificação do imaginário entre os dois pólos: colonizador/ colonizado. Torna-se, então, impossível uma materialidade hegemônica quando se pensa no aspecto cultural que permeia as produções literárias dos países colonizados, uma vez que o que se evidencia é a relação imagética interconstituída.

Knopfli constrói um discurso que não deixa de estar em consonância com os demais, contudo, segue uma linha mais intimista e com um fluido diálogo com os clássicos da literatura ocidental e longe das apologias nacionalistas, fugindo à estética literária padronizante que vigia à época. $\mathrm{O}$ fato mesmo de ter ascendência europeia em terra africana contribuiu para que sua obra passasse a refletir a divisão entre esses dois mundos culturais e geográficos (ocidental e africano) o que explica a impregnação no seu discurso poético de uma melancolia, de um tom seco e austero, observa o poeta: "Doente, nada tenho de bucólico para fazer. [...] Estrangulada nos fios a minha voz" (KNOPFLI, 2003, p.55). Dentro desse discurso colonialista há, portanto, os sujeitos que foram escravizados e silenciados pelo sistema e pela política coloniais, temos os sujeitos representantes do poder colonialista escravocrata e, também, os sujeitos que nasceram à sombra da mescla cultural engendrada nesse período histórico e que sofreram com este processo de submissão das colônias tanto quanto os próprios sujeitos escravizados.

Há dois modos, generalizando a afirmação, de se perceber tal ponto de vista, ainda que se complementem ao largo de seu entendimento. O primeiro vem pela obra do crítico cultural Edward Said, quando em Cultura e Imperialismo (2011), ao estabelecer uma argumentação sobre as migrações e os efeitos de sentido que esses movimentos migratórios causam, recupera as palavras de Ali Shariati. Diz ele que o homem,

esse fenômeno dialético, é obrigado a estar sempre em movimento. [...] O homem, assim, nunca pode atingir um descanso final e fixar morada. [...] Como são vergonhosos, então, todos os padrões fixos. Quem jamais poderá fixar um padrão? O homem 
é uma "escolha", uma luta, um constante vir a ser. Ele é uma migração infinita, uma migração dentro de si próprio. [...] Ele é um migrante dentro de sua própria alma (apud Said, 2011, p. 507).

A partir de tais considerações do intelectual islâmico citado por Said, podemos perceber o quão padece o sujeito que, não sendo colonizador nem colonizado, passa a movimentar-se em migrações íntimas na busca de um eu totalizante e pleno de sentido e de uma aceitação por parte de uma formação discursiva vinculada a um discurso sócio-cultural e político que de início discriminava o negro e o branco que não compactuavam com as aberrações impostas pelo sistema colonialista. E que depois do período de libertação do regime colonial passou a não aceitar o branco que não aderisse à luta pela libertação de forma contundente. Ou seja, este referido sujeito está sempre buscando um espaço de pertença que lhe foi negado pela contextualização histórica. Um ator social que busca não "Ser estranho na própria terra" (KNOPFLI, 2003, p. 80). Ou, ainda, como observa a voz do poeta: "europeu me chamam, mas africano sou. Trago no sangue uma amplidão de coordenadas geográficas e mar Índico (KNOPFLI, 2003, p. 59). [...] Metade de mim persiste, vive (KNOPFLI, 2003, p. 150). Os versos representam um pouco da sensação do sujeito poético knopfliano em sua luta íntima para achar uma definição de completude existencial.

O outro modo que vai ratificar a ideia de que o sujeito que está inserido no entremeio da dialética colonial agoniza com a sua impossibilidade de chegar a ser aceito plenamente pelo seu espaço-nação, vem das palavras de Frantz Fanon (2008) quando trabalha na sua obra Pele negra, máscaras brancas a metáfora do "sonho de inversão" que diz que não é o EU-colonizador nem o Outro-colonizado que vão constituir a figura da alteridade colonial, mas sim o espaço entre os dois, levando a uma complexa relação de alteridade. Nesse processo inter-relacional da constituição de identidades, a alteridade do branco constitui o negro e vice-versa, e, assim, instaura-se o hibridismo no âmago da identidade.

Os poemas que seguem vão desvelar essa condição híbrida e conflitante em que o sujeito poético ora se encontra na formação ideológica² do colonizador ora está inserido na formação ideológica do colonizado.

\section{O CAMPO}

Saio para o campo. O campo/aqui não é o campo, mas a savana/eriçada de micaias e capim/feio e desigual. Habitantes/do seu mundo, os negros ignoram-me,/empenhados em suas tarefas cotidianas./Olho para as coisas abandonadas,/latas escuras de ferrugem, lonas/pardas de pneus, ferro/retorcidos sem jeito. Entre isso/o capim espreita, descolorido, espigado/e hirsuto. Nada me sugere a face/aveludada de uma paisagem pastoril,/rosto tranquilo de criança sonhando./Mas eles estão no seu mundo,/e eu passeio no campo (KNOPFLI, 2003, 154).

O sujeito poético, nos versos acima, demonstra sua condição de apartado dos negros, habitante de um compósito imagético em que o espaço "campo" representa o espaço europeu e a "savana", o espaço africano. Esta diferenciação vai representar o lugar que cada sujeito deve ocupar no processo antagônico da colonização. Bhabha (2007, p.98) ao

2 Para Pêcheux e Fuchs - 1975 - (1993, p.166), a formação ideológica (FI) constitui-se num elemento capaz de intervir, como uma força que se opõe a outras forças, na conjuntura ideológica característica de uma formação social, em um momento específico. Assim, cada FI se constitui em num conjunto complexo de atitudes e representações que não são individuais nem universais, mas que se relacionam mais ou menos diretamente a posições de classes em conflito umas com as outras. 


\section{Conexão Letras}

tratar da questão de identidade no contexto pós-colonial, dialoga com Fanon para explicar que o sujeito ao negar a condição diferenciada do mundo colonial (um sujeito inferior ao outro), faz com que o representante do colonialismo se vincule à ambivalência da identificação paranóica, alternando entre fantasias de megalomania e perseguição. O que pode causar um esvaziamento do eu racista que projeta essa imagem. Isto pode ser observado quando o sujeito poético se vê como alguém ignorado pelos negros, diz ele: "habitantes do seu mundo, os negros ignoram-me". E sendo colonizador só lhe resta voltar-se para seu mundo quando, categoricamente, observa: "eu passeio no campo", deixando-os nas suas "tarefas cotidianas".

No poema Anemoscopia, que é composto por estrofes subtituladas, são destacados dois recortes discursivos:

\section{O SILOGISMO NOCTURNO}

Duramos através da noite/a escrutar-lhe os segredos possíveis./A realidade/húmida do palato, /a superfície estranha dos dentes, /pesam sobre a língua gredosa / uma outra dimensão. Toda/a importância escura/de um povo nos assoma/e, transidos, escutamos o latejar/elástico das sombras na sombra./E não são imaginados espectros, são dedos/frios, desfibrando, agudos, o sono/da consciência./São finas lâminas,/ facas de agoiro, penetrando a carne/do remorso. Um povo escuro/dolorosamente nos incomoda/a tranquilidade do silogismo nocturno,/perfeitamente nítido,/sob o equívoco, a neurastenia,/a insônia, o café a mais/e o amargo sabor do tabaco (KNOPFLI,2003,181).

E, ainda, o excerto:

\section{CERTIDÃO DO ÓBITO}

Um tempo de lanças nuas/espera por nós, riso/cruel de maxilas em riste./Entanto a vida desabrocha/tenra e tépida,/fruto e flor na noite secular/de quem tanto esperou em vão./Para nós, todavia,/o tempo é de lanças impiedosas,/de lâminas em cuja brancura/ se adivinha já um indício/do nosso sangue. Deste tempo/sobrou-nos o acerado das lanças:/este o quinhão ácido que nos coube/ e que mastigamos resignadamente./Entanto, num levedar de ternura./frágil e muito bela, a vida desponta/na negra poupa de outros dedos./Para nós, o prêmio do aço,/ a estrela da pólvora, a comenda do fogo./ Para nós a consolação do sorriso triste/e da amargura sabida. Falamo-nos/ e nas palavras mais comuns/há rituais de despedida. Falamos/e as palavras que dizemos/ dizem adeus (KNOPFLI, 2003, 182-183).

O sujeito poético, nas passagens anteriores, ora é um "nós" colonizador quando observa que "Toda a importância escura de um povo nos assoma [...] Um povo escuro dolorosamente nos incomoda"; ora é um "nós" colonizado: "Para nós, todavia, o tempo é de lanças impiedosas [...] sobrou-nos o acerado das lanças [...] Para nós, o prêmio do aço". E é nesta volubilidade que o sujeito representa sua condição híbrida, de modo que seu discurso vai revelando uma ambiguidade que lhe é constitutiva. Ao falar do entre-lugar Bhabha (2011, p.90) retoma Bakhtin esclarecendo que o híbrido não tem somente uma dupla voz, um duplo sotaque, mas uma dupla língua e duplicações de consciências sóciolinguísticas. É, então, a partir dessa condição conflitante que Knopfli alicerça boa parte da sua obra poética, visto que, ao pensarmos junto com Said (2011, p. 510), que o imperialismo consolidou a mescla de culturas e identidades, de tal modo que ninguém é uma coisa só; e estando a obra knopfliana inserida num contexto histórico que demonstra 
isto, os poemas do autor revelam expressivamente essa condição dupla em que o sujeito se constituiu. Os dois poemas que seguem refletem significativamente o poeta em busca de uma identidade, acentuadamente conflituosa e pluri-imagética:

\title{
Naturalidade
}

Europeu, me dizem./ Eivam-me de literatura e doutrina/ europeias/ e europeu me chamam./ Não sei se o/ que escrevo tem a raiz de algum/ pensamento europeu./ É provável ... Não. É certo,/ mas africano sou./ Pulsa-me o coração ao ritmo dolente/ desta luz e deste quebranto./ Trago no sangue uma amplidão/ de coordenadas geográficas e mar Índico./ Rosas não me dizem nada,/ Caso-me mais à agrura das micaias/ e ao silêncio longo e roxo das tardes/ com gritos de aves estranhas./ Chamais-me europeu? Pronto, calo-me./ Mas dentro de mim há savanas de aridez/ e planuras sem $\mathrm{fim} /$ com longos rios langues e sinuosos,/ uma fita de fumo vertical,/ um negro e uma viola estiolando (KNOPFLI, 2003, p.59).

E, ainda:

\begin{abstract}
Auto-Retrato
De português tenho a nostalgia lírica/ de coisas passadistas, de uma infância/ amortalhada entre loucos girassóis e folguedos; / a ardência árabe dos olhos, o pendor/ para os extremos: da lágrima pronta/ à incandescência súbita das palavras contundentes,/ do risco claro à angústia mais amarga./ De português, a costela macabra, a alma/ enquistada de fado, resistente a todas/ as ablações de ordem cultural e o saber/ que o tinto, melhor que o branco,/ há-de atestar a taça na ortodoxia/ de certas virtualhas de consistência e paladar telúrico./ De português, o olhinho malandro, concupiscente/ e plurirracial, lesto na mirada ao seio/ entrevisto, à nesga de perna, à fímbria de nádega;/ a resposta certeira e lépida a dardejar nos lábios,/ o prazer saboroso e enternecido da má-língua./ De suíço tenho, herdados de meu bisavô,/ um relógio de bolso antigo e um vago, estranho nome (KNOPFLI, 2003, p.259).
\end{abstract}

No poema "Naturalidade", percebe-se a expressão de um sujeito cindido e identificado com dois espaços de auto-representação. No que se refere à expressão e representação emotivas, exalta o espaço africano, e com relação ao espaço intelectual, vincula-se à tradição literária e de pensamento portuguesa e ocidental. Esse duplo espaço de identificação torna a poesia de Knopfli singular dentro do contexto das literaturas de língua portuguesa na África, visto que vai na contramão dos demais discursos dos intelectuais africanos da época. Esse discurso poético-híbrido representa um sujeito em um movimento autoconstrutivo e de desconstrução, simultaneamente, que lança um olhar crítico sobre a projeção que lhe incutem de uma identidade exclusivamente europeia. Ao distanciar-se, criticamente, o sujeito-poeta manifesta em seu discurso a identidade que tanto reclama - a africana ("mas africano sou"). No outro poema, "Auto-Retrato", o autor evidencia uma expressão mais irônica quanto à sua condição de sujeito híbrido, como forma de expressar seu descontentamento em relação ao modo impositor dos que lhe negaram, inicialmente, a inserção nos círculos da poesia contemporânea de Moçambique, pelo fato de buscar inspiração na literatura ocidental e de não se engajar no discurso libertário anticolonial.

Podemos pensar que esse recurso estilístico da ironia reforça ainda mais o seu desejo de libertar sua voz cerceada, visto que a ironia segundo Orlandi (1983) estabelece uma região significante em que simulações, alusões e rupturas de significação podem ser desenvolvidas com o intuito de possibilitar um jogo entre as formas de mundo já dadas 
(mundos fixados, senso-comum) com outros estados de mundo, causando eco e ruptura. O discurso irônico possibilita ao sujeito-poeta colocar em causa as convicções acerca do ideológico, cultural, linguístico, político, etc.

A ironia pressupõe, dessa forma, a congruência e a solidez dos discursos instituídos e aproxima elementos com sentidos incongruentes, produzindo, assim, um discurso poético com efeito dissonante. A ironia, ainda consoante a Orlandi, contempla a literalidade e simultaneamente a desloca, produzindo um estranhamento, portanto, é um modo de significar que constitui o processo em que, na linguagem, o sujeito-poeta se nega e se reconstrói, e nesse processo de reconstrução a ironia assume um efeito de discurso crítico. A condição de sujeito submerso em um espaço pós-colonial reflete uma interação complexa entre língua

história e meio ambiente denunciando em regra um senso de deslocamento e inadequação linguística da parte do sujeito de escrita pós-colonial, em particular quando as origens culturais e geográficas desse sujeito não se encontrem no espaço colonizado onde se realiza essa escrita (ASHCROFT apud Monteiro, 2003, p.53).

Knopfli vai apresentar em sua obra este sujeito que, não sendo o negro escravizado nem o mestiço, passa após o período de libertação do sistema colonialista, a sofrer por não fazer parte incisivamente da formação discursiva totalmente inserida na luta pela libertação do jugo europeu.

No período de transição (de colônia à independência) da história moçambicana, muito se produziu em termos literários, porém não era qualquer obra que podia ser publicada. Se antes era a metrópole, através de seus postos administrativos, que vigiava as publicações, depois, no período pós-independência (após 1975), passou a ser a FRELIMO (Frente de Libertação de Moçambique) que autorizava o que poderia ser publicado dentro do contexto revolucionário. Monteiro (2003, p.27) vai apresentar uma entrevista na qual Knopfli fala sobre o discurso da FRELIMO. Afirma o escritor que "[...] Quando a FRELIMO tomou conta do poder, o inimigo era o português, estou convencido disso. Claro que havia um certo racismo, aliás compreensível, mas, mesmo aí, os brancos eram identificados com os portugueses".

Alguns escritores, conforme nos indica Laranjeira (1995), descendentes de portugueses, acabaram saindo da sua terra natal para países europeus, por se sentirem deslocados. Começam a publicar, desde então, principalmente, em Portugal. Knopfli foi um destes escritores que, mesmo saindo de Moçambique, não deixou de escrever sobre a ilha e de reivindicar ser sujeito nascido e criado na África. O que revela também em entrevista:

A verdade é que eu nunca poderia sentir como um europeu. Porque eu era só filho de europeus. A Europa para mim era só uma ideia [...] e todas as minhas vivências, aquelas que me tocavam mais de perto o coração, a não ser as culturais, eram todas de origem africana. [...] Eu nunca reivindiquei a nacionalidade moçambicana, só reivindiquei um facto, [...] de ser africano" (MONTEIRO, 2003, p.26).

É este sujeito cindido e híbrido que vai aparecer na obra knopfliana, que ao sentir-se fora do lugar põe-se em marcha a um outro espaço que não se configura como oposição do seu ponto de partida, ficando assim, em uma outra margem - a terceira, confluindo com o que Bhabha (2007) chama de entre-lugar.

Investigar a obra de um escritor das literaturas da África lusófona pressupõe trabalhar com as áreas de estudos que reveem a condição colonial em um aspecto menos binarista, 
deve-se, conforme Hall (2003, p.108-109), pensar a diferença entre colonizador e colonizado não em termos de um "antes" e um "agora", mas os binarismos devem ser relidos como formas de transculturação, de tradução cultural, de modo a romper com a ideia do dentro/ fora do sistema colonial. Pensando a partir desse preceito é que Hall designa o termo pós-colonial não somente como um período histórico que descreve uma determinada sociedade ou época. O pós-colonial é um período que relê a colonização como um processo global com uma essência transnacional e transcultural, que vai deslocar as noções de centro e periferia, de modo que o global e o local se reorganizam e se moldam um ao outro. Então, não se pode pensar o pós-colonial como um período que encerra o colonial, com vistas a crer que os efeitos do colonialismo já se desfizeram com o passar dos tempos.

Pensando o seu trabalho como estudiosa das literaturas africanas, Leite (2012, p.317), vai trazer um aspecto importante, a seguir, para quem pesquisa o discurso literário advindo de um contexto histórico tão complexo: "É essa tensão entre o epistemológico e o cronológico que se revela produtiva. Uma vez que as relações que caracterizam o "colonial" não ocupam agora o mesmo lugar - são movediças e insidiosas nessa era global - ou a mesma posição relativa, e podemos não somente tentar identificá-las, criticá-las, mas, sobretudo, desconstruí-las".

É nesse espaço de desconstrução que se tem de verificar como a produção poética de Rui Knopfli se torna exemplar para desvendar a condição do sujeito híbrido que veio a se constituir a partir da ruptura com o espaço histórico homogeneizante e centralizador de poder. Se antes as regras culturais eram ditadas pelo colonizador, depois veio a se pensar o espaço cultural como uma relação de mútuas influências e já não se pode pensar, unilateralmente, em cultura do colonizador e do colonizado, mas na confluência entre essas culturas.

Importante pensar junto com Said (2011, p.510) que a sobrevivência a todo o processo de desagregação que ainda afeta o mundo está no modo como os sujeitos encaram os outros ecos, e se torna mais compensador pensar sobre os outros em termos concretos, empáticos, contrapontísticos, do que pensar somente sobre si mesmo. E isso significa não tentar dominar os outros, não tentar classificá-los, tampouco, hierarquizá-los e, sobremaneira, não reproduzir um discurso em que se exalta a própria cultura em detrimento de outra.

A construção da identidade no espaço colonial é uma passagem do psíquico ao político, num processo conflitante e ambíguo e como nos ensina Fanon (2008) esse espaço perturbador entre o eu colonizado e o Eu do colonizador vai instaurar a figura da alteridade colonial, de modo que a alteridade de um constitui a alteridade do outro inaugurando, assim, o hibridismo nesse processo relacional de configuração de identidades.

Com essa configuração híbrida do sujeito as formas culturais dominantes passam a ser "crioulizadas", havendo, assim, conforme explica Hall (2003, p.34-35), a desarticulação de certos signos e a rearticulação de outra forma cultural com outro significado simbólico. É o que ele chama de "nova cultura", que é advinda, então, das mesclas culturais do colonizador e do colonizado (pós-colonialismo). Essa "nova cultura" não poderá ser pensada como um retrocesso ao lugar em que se estava antes, mas sim considerar que há "algo no meio", espaço da cultura em que o colonizado está submerso depois do pós-colonial. É de suma importância acrescentar que não somente o colonizado está submerso, mas também o sujeito descendente de europeu que nasceu em terras africanas está inserido nesse entremeio simbólico-culutral, o que está latente na obra poética de Knopfli.

Em consonância com o que relata Bhabha (2007,p.20) é crucial passar a focalizar momentos e processos culturais que são produzidos na articulação de diferenças culturais e pensar que esses entre-lugares fornecem o terreno para a elaboração de estratégias de 
subjetivação, tanto singular quanto coletiva, que dão início a novos signos de identidade e criam lugares de colaboração e contestação, no processo que vai definir a própria ideia de sociedade. Pesquisar o discurso poético knopfliano vai corroborar com essa estratégia a que nos incita Bhabha: a de repensar os estudos culturais e literários, focalizando não somente no discurso opositor do binarismo colonizador/colonizado, mas fazendo emergir o discurso que está no entremeio dessa relação desigual.

Para entender essa forma de representação é primordial entender, conforme o autor, o que ele designa por lócus de enunciação, ou seja, o contexto e as condições sócio-históricas de produção e interpretação de um dado discurso. Esse lócus é atravessado por uma gama heterogênea de ideologias e valores sócio-culturais que constituem os sujeitos; é o "terceiro espaço" em que todo discurso contraditório e conflitante de elementos linguísticos e culturais interagem constituindo o hibridismo.

Ademais do que foi referido, observa-se nos poemas de Knopfli outras formas de expressar o sujeito dividido e híbrido que compõe sua obra. Através da relação dialógica com os escritores ocidentais (europeus e brasileiros), o sujeito poético knopfliano vai mostrar como as influências ocidentais fazem parte da constituição da sua obra e da sua cultura híbrida. Dialogando, então, com Pessoa no poema O Poeta é um Fingidor, quando enuncia: "Estabeleço assim dois mundos divergentes:/ A textura entristecida dos versos/ e a tristeza entretecida da alma" (KNOPFLI, 2003, p.222); com Camões em Glosa de Camões, ao recuperar a imagem da perenidade da vida: "Até que no tempo cesse anônimo/ o tênue sopro que ao tempo dou” (KNOPFLI, 2003, p.334) e, também, com Shakespeare, em Glosa de Shakespeare, ao cantar a brevidade da matéria: "Não chores por mim quando tiver morrido/ mais do que o tempo de meu corpo baixar à terra." (KNOPFLI, 2003, 332). O poeta, além dos clássicos ocidentais, lê e é influenciado pela literatura brasileira, assim como grande parte dos escritores africanos de língua portuguesa. Faz-se bem lembrar que os brasileiros passam a ser lidos na África, principalmente, a partir dos anos 40, por haver uma identificação com o período de escrita de cunho regional que surgia nas narrativas de Graciliano Ramos, José Lins do Rego, Jorge Amado entre outros. Na poesia, muitos escritores africanos liam, assim como Knopfli, Carlos Drummond de Andrade, Manuel Bandeira, Vinícius de Moraes e seus contemporâneos que conseguiam cruzar o oceano e chegar às mãos de além-mar. Por isso, em sua obra poética, pode-se notar uma intertextualidade com esses consagrados poetas brasileiros que permearam sua produção poética. Essa influência está evidente em poemas como A Pedra no Caminho, Terra de Manuel Bandeira e Nunca Mais é Sábado.

A poética knopfliana ainda apresenta uma forte relação com o espaço da ilha de Moçambique, ao mesmo tempo, em que o sujeito poético versa em um tom saudosista falando da sua "Muipíti, velha ilha, metal remanchado, minha paixão adolescente", ele vai revelando sua condição de não-pertença a este lugar que desde seu primeiro livro designou como $O$ País dos Outros. São muitos os versos que expressam essa condição, que através do resgate do ambiente, da natureza, dos rios, de forma exemplar e evasiva vão desvelando o maior desejo do sujeito poético, como no verso que segue: "Mas retomo devagarinho as tuas ruas vagarosas" (2003, p.349). Enquanto não é possível de fato viver esse retorno, através do ato poético o poeta revela seu profundo sofrimento de não-pertença num tom melancólico, regado por vozes ciciadas e por um som etéreo descarnando o silêncio: "Assim arrasto a minha inutilidade/ e lembranças como feridas [...] / como o sonho esboroado daquilo que não fui" (KNOPFLI, 2003, p.64). Ou ainda, ao dizer "[...] o orgulho que nada venceu, / nem o ser estranho na própria terra” (KNOPFLI, 2003, p.80). 
O enriquecedor da obra de Rui Knopfli é justamente a capacidade de representar mundos tão diferentes e tão permeados pelo seu desejo de reerguer-se como sujeito, de permitir-se ser, num contexto em que ao sujeito era-lhe negado fugir ao sussurro. E nessa peleja contra o silenciamento, o silêncio se torna muito mais que eco, muito mais que gesto, é o próprio sentido mesmo de tudo, de si: "Escrevo contra o silêncio. Eu não tenho já nome aqui, a minha voz nasce no deserto, vertical e desnuda, e rompe lâmina cega, porém exacta; bate na pedra".

\section{Refefências}

ABDALA JUNIOR, B. Literatura, História e Política: Literaturas de Língua Portuguesa no Século XX. Cotia, SP: Ateliê Editorial, 2007.

BHABHA, H. O Local da Cultura. Belo Horizonte: Editora da UFMG, 2007.

O Bazar Global e o Clube dos Cavalheiros Ingleses: Textos Seletos. (org.)

COUTINHO, E. Rio de Janeiro: Editora Rocco, 2011.

FANON, F. Pele Negra, Máscaras Brancas. Salvador: EDUFBA, 2008.

HALL, S. Da Diáspora: Identidades e Mediações Culturais. (org.). SOVIK, L. Belo Horizonte: Editora da UFMG, 2003.

KNOPFLI, R. Obra Poética. Lisboa: Editorial da INCM, 2003.

LARANJEIRA, P. Ensaios Afro-literários. Coimbra: Novo Imbondeiro, 2001.

. Literaturas Africanas de Expressão Portuguesa. Vol. 64, Lisboa: Universidade Aberta, 1995.

LEITE, A. M. : Estudos Sobre Literaturas Africanas. Rio de Janeiro: EDUERJ, 2012. LOPES, O. \& SARAIVA, A.J. História da Literatura Portuguesa. Porto: Porto Editora, 2012.

MAZRUI, A. A.; WONDJI, C. (Ed.). História Geral da África: África Desde 1935.

Vol. VIII. São Paulo: Cortez Editora; Brasília: UNESCO, 2011.

MONTEIRO, F. O país dos outros: a poesia de Rui Knopfli. Lisboa: Editorial da INCM, 2003.

ORLANDI, E. Destruição e construção do sentido: um estudo da ironia. In: Colóquio do Departamento de Linguística do IEL. Campinas: Editora da UNICAMP, 1983.

PÊCHEUX; FUCHS. 1975 - A Propósito da Análise Automática do Discurso: Atualização e Perspectivas. In: GADET; HAK (Org.). Por uma Análise Automática do Discurso. Campinas: Editora da UNICAMP, 1993.

SAID, E. W. Cultura e Imperialismo. São Paulo: Companhia das Letras, 2011. 